\title{
Girdle Sensation Caused by Radiculitis due to Neurosarcoidosis
}

Junpei Kobayashi, Naoto Sugeno, Aya Shibui and Masashi Aoki

Key words: girdle sensation, thoracic radiculitis, dorsal root, magnetic resonance imaging, sarcoidosis

(Intern Med 54: 1567-1568, 2015)

(DOI: 10.2169/internalmedicine.54.4242)

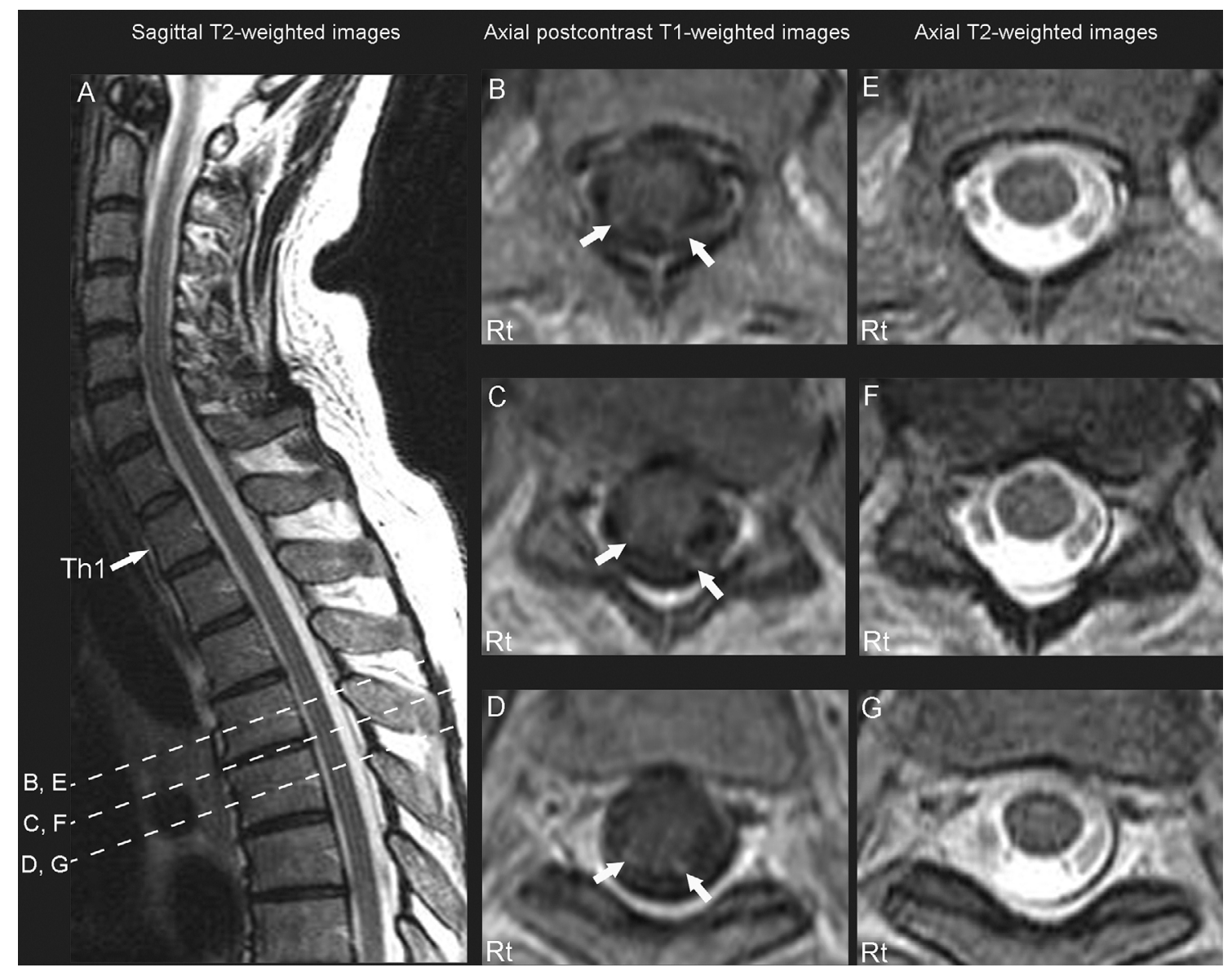

Picture.

A 46-year-old woman suffered from unbearable tightness in the chest and difficulty in closing her eyes for over 1.5 months. A neurological examination revealed $\mathrm{V}_{1,2}$ and facial nerve palsies, absent patellar and Achilles tendon reflexes, a positive Lasègue sign and girdle sensation corresponding to the Th2-8 dermatomes. Blood tests, including measurements of the angiotensin-converting enzyme level, were all normal.

Brain and spinal magnetic resonance imaging showed no intramedullary spinal lesions; however, remarkable gadolinium enhancement of the Th2-7 dorsal roots (Picture), both trigeminal nerve entries and right geniculate ganglion was noted. Non-caseating epithelioid cell granuloma formation 
originating from the supraclavicular lymph node led to the diagnosis of probable neurosarcoidosis. Although the girdle sensation was intractable, the patient's other neurological symptoms gradually improved following the initiation of treatment with oral corticosteroids.

Cases of neurosarcoidosis presenting with the girdle sensation due to thoracic radiculitis have been reported (1), although the anatomical localization was primarily determined based on the exclusion of intramedullary spinal lesions. In the current case, we showed direct evidence of radiculitis detected as bilateral dorsal root enhancement.

The authors state that they have no Conflict of Interest (COI).

\section{Reference}

1. Yakushiji Y, Yamada K, Nagatsuka K, Hashimoto Y, Miyashita K, Naritomi H. "A girdle-like tightening sensation" misapprehended as abdominal splanchnopathy in a sarcoidosis patient. Internal Med 44: 647-652, 2009.

(C) 2015 The Japanese Society of Internal Medicine http://www.naika.or.jp/imonline/index.html 